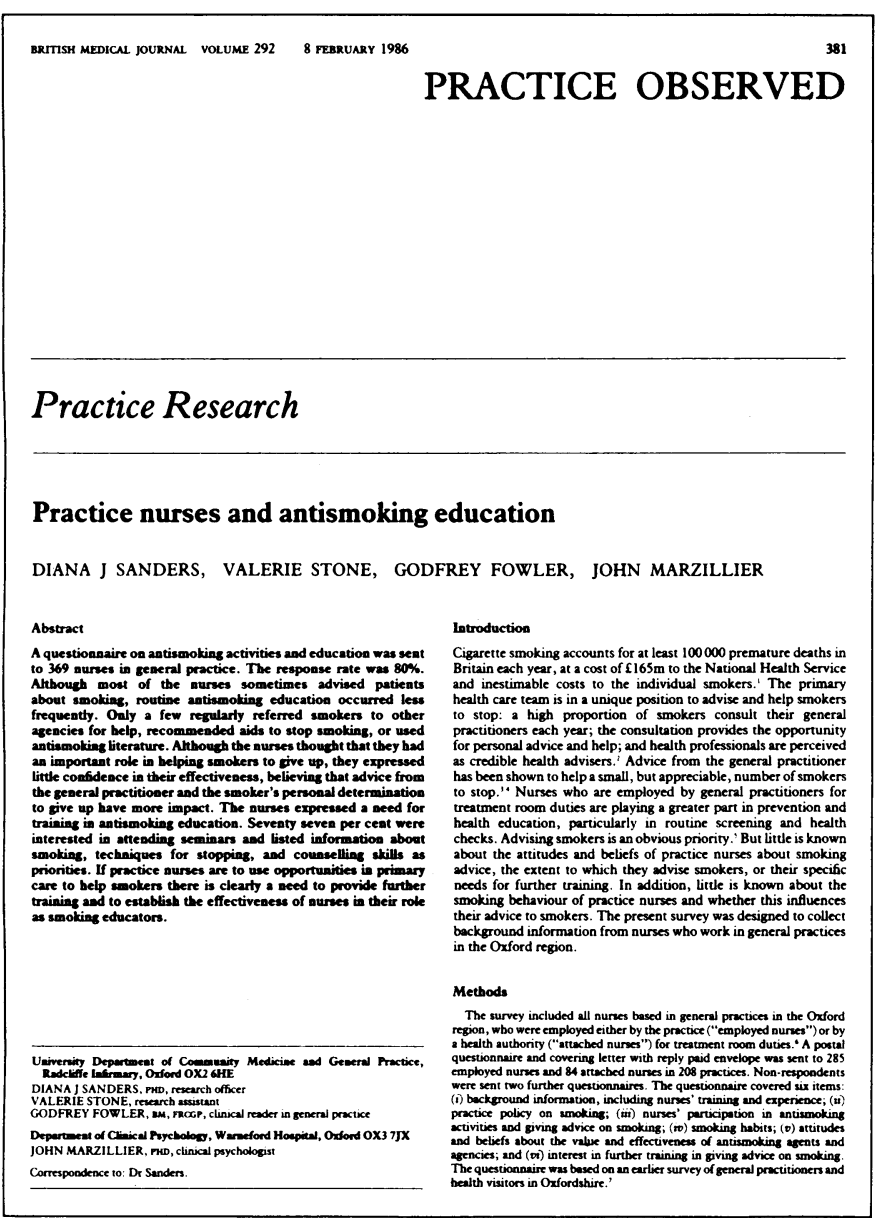

\begin{tabular}{|c|c|}
\hline 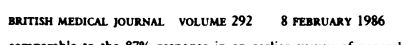 & \\
\hline 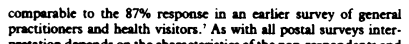 & 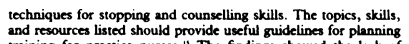 \\
\hline 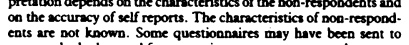 & 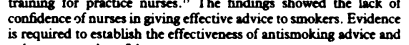 \\
\hline 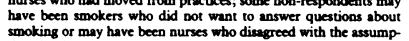 & 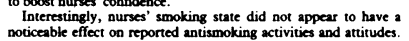 \\
\hline & 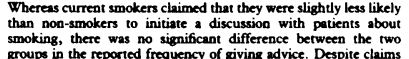 \\
\hline 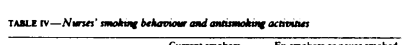 & 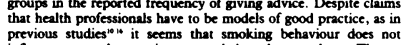 \\
\hline and & 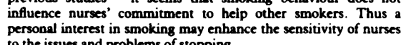 \\
\hline 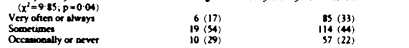 & 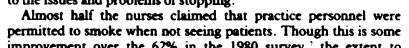 \\
\hline 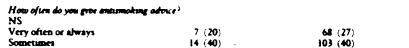 & 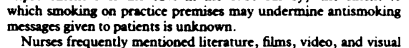 \\
\hline 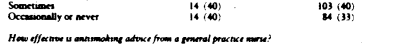 & 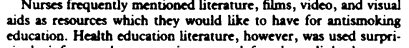 \\
\hline 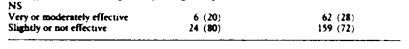 & 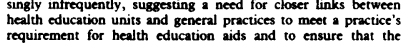 \\
\hline & 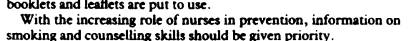 \\
\hline 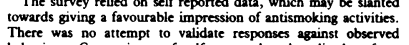 & 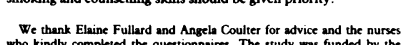 \\
\hline 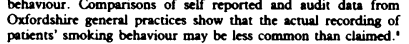 & 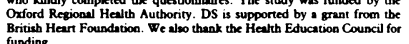 \\
\hline 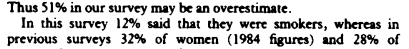 & \\
\hline 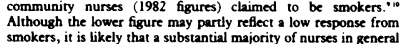 & 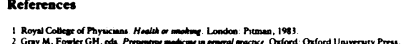 \\
\hline 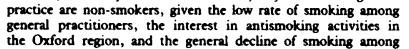 & 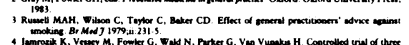 \\
\hline 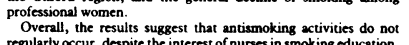 & $\therefore=15=$ \\
\hline 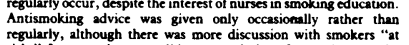 & 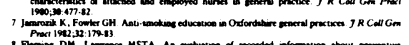 \\
\hline 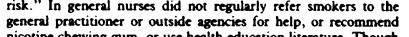 & $=1$ \\
\hline 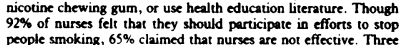 & 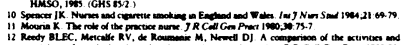 \\
\hline 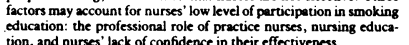 & $=4$ \\
\hline 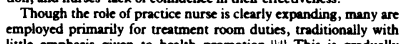 & 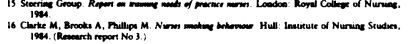 \\
\hline 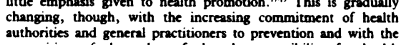 & 烈 \\
\hline 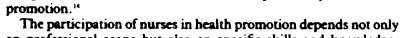 & Matticultural mediciciere \\
\hline 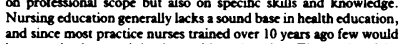 & 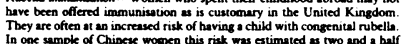 \\
\hline 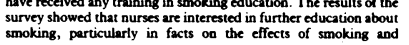 & 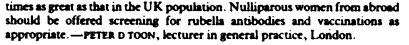 \\
\hline
\end{tabular}

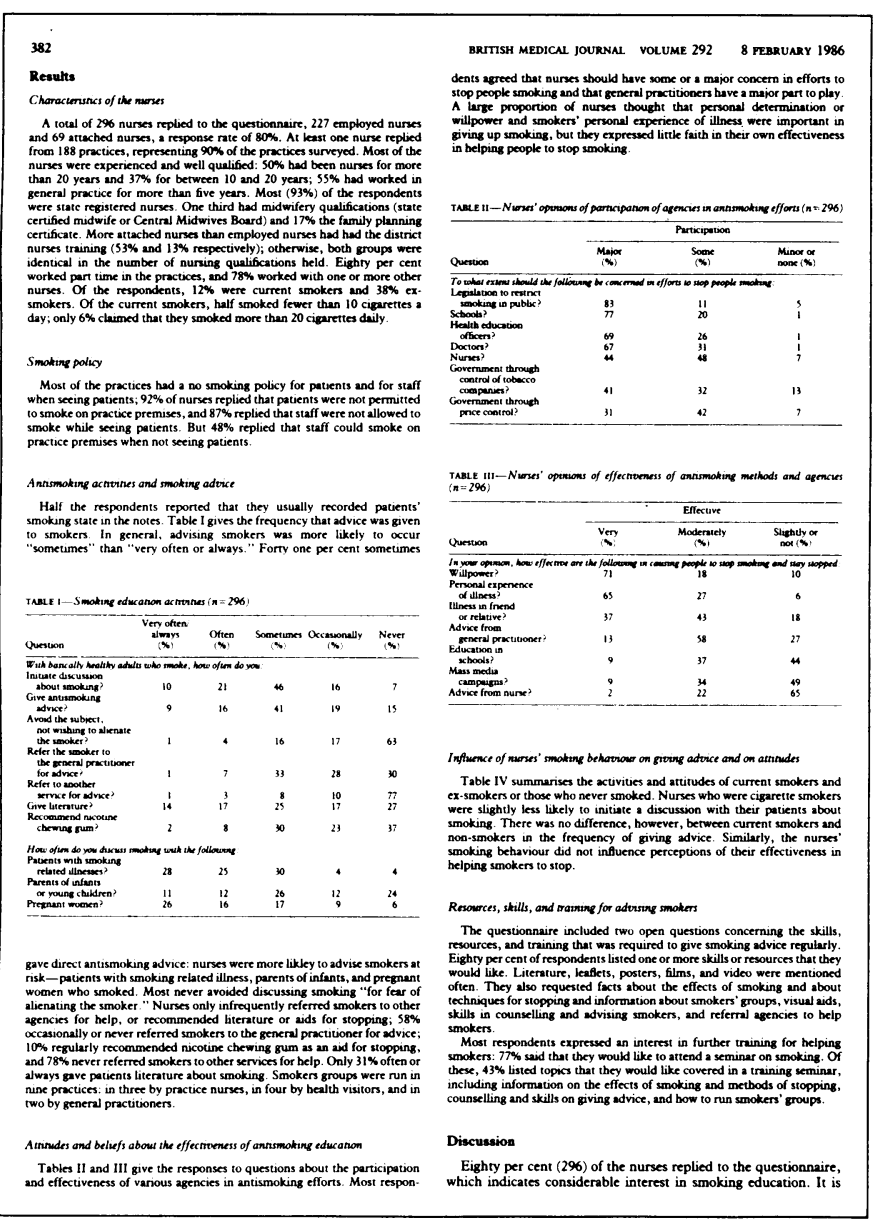

\begin{tabular}{|l} 
Aut \\
\hline Audit Report
\end{tabular}

\title{
Treatment of hypertension: review necessary after screening
}

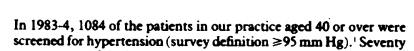

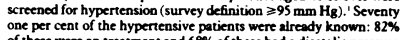

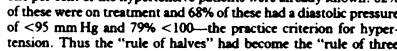

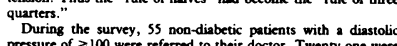

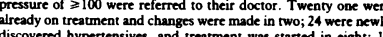

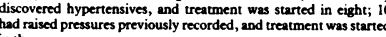

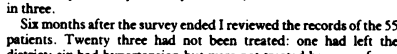

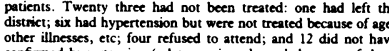

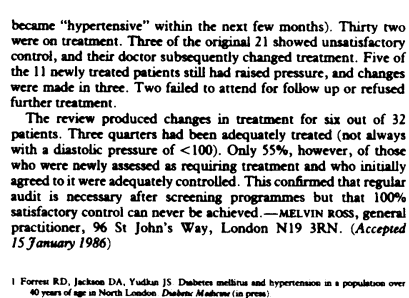

100 YEARS AGO

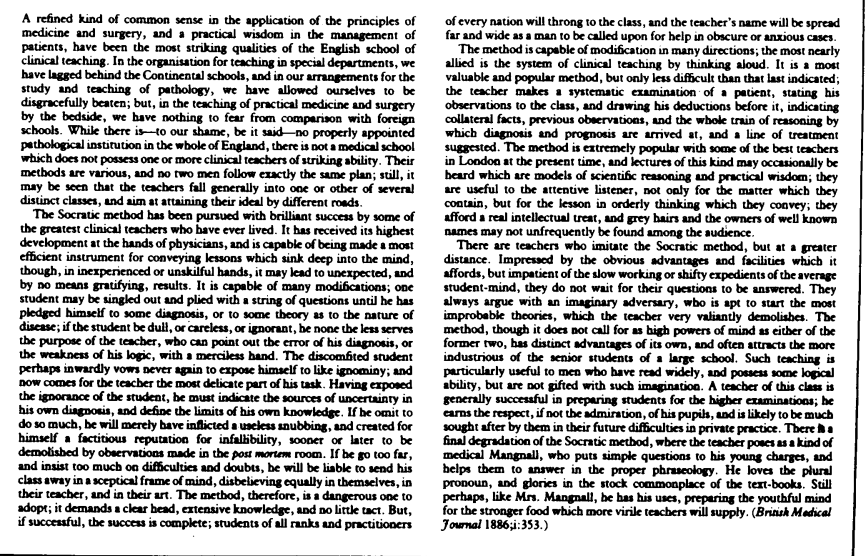

